\title{
0 fim com vistas ao qual um homem escolhe viver (Ética Eudêmia I 5, 1215 $\left.{ }^{\mathrm{b}} 15-16^{\mathrm{a}} 10\right)^{1}$
}

Raphael Zillig

rzillig@gmail.com

Universidade Federal do Rio Grande do Sul (UFRGS), Porto Alegre, Brasil CNPq

resumo No início de Ética Eudêmia I 5, Aristóteles pretende mostrar que a questão “o que é a felicidade?" não é tão facilmente respondida como se crê usualmente. 0 modo como ele procura fazê-lo, no entanto, é intrigante, uma vez que ele recorre ao exame de diferentes situações nas quais não viver seria mais vantajoso do que viver. Não é claro como ele espera que estejam relacionadas entre si as diferentes situações que levam a essa conclusão nem como ele pretende que essa linha de argumentação esclareça a dificuldade que é normalmente ignorada com relação à questão “o que é a felicidade?". Neste artigo, discutimos esses pontos com o objetivo de determinar a contribuição da porção inicial de EE I 5 para a investigação eudêmia da felicidade.

palavras-chaves Aristóteles; felicidade; fim; vida; humanidade; bem

\section{Introdução}

Aristóteles dedica o início do capítulo 5 de Ética Eudêmia (EE) I (precisamente de $\left.1215^{\mathrm{b}} 15-16^{\mathrm{a}} 10\right)$ a mostrar que, contrariamente à impressão geral, não é fácil julgar a respeito do que seja a felicidade (દủరaınovia). A argumentação apresentada costuma causar desconforto aos intérpretes, uma vez que a estrutura da argumentação não é de todo clara, nem tampouco são transparentes as conexões do trecho com o contexto no qual está inserido ${ }^{2}$. Tentaremos, aqui, propor uma interpretação para o trecho que seja capaz de integrá-lo à discussão que Aristóteles desenvolve até então, esclarecendo um conjunto de características gerais da عủסaınovía que não haviam, ainda, sido discutidas.

Recebido em 20 de maio de 2013. Aceito em 13 de setembro de 2013. doispontos, Curitiba, São Carlos, vol. 10, n. 2, p.357-371, outubro, 2013 


\section{A argumentação em seu contexto}

EE I 5 começa com a afirmação segundo a qual "se não é fácil julgar corretamente acerca de muitos outros assuntos, é sobretudo dificil julgar acerca do que a todos parece ser o mais fácil e cujo conhecimento parece pertencer a todo homem: o que na vida cabe escolher [Ti Tûv $\dot{\varepsilon} v$

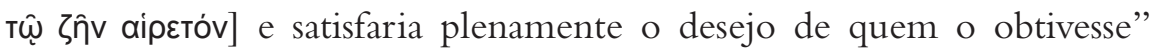
$\left(1215^{\mathrm{b}} 15-18\right)^{3}$. A argumentação que pretendemos examinar é introduzida com um yáp na linha seguinte e, portanto, tem por objetivo fundamentar essa primeira afirmação. Após a exposição das razões que fundamentariam a afirmação inicial, Aristóteles encerra o trecho com a seguinte afirmação: "Desse modo, é evidente, a partir dessas coisas, que escapa aos que investigam o que é o bem-viver e o que é o [maior] bem no viver." (1216ª9-10)

Tanto o vocabulário do início do texto, quanto o da conclusão deixam claro que Aristóteles está falando da dificuldade de se determinar o que é a felicidade. No entanto, as diferentes expressões que ele usa podem in-

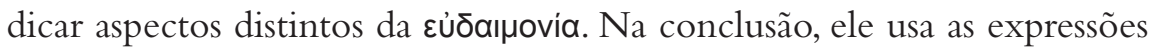

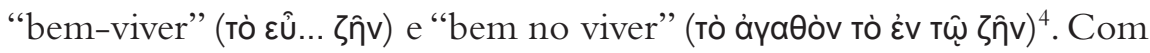
essas expressões, Aristóteles afirma que é dificil dizer i) o que significa

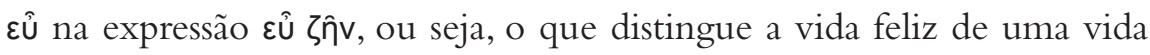
qualquer e ii) o que é o áyaӨóv no viver, ou seja, o que é, por excelência o bem no viver. Em outras palavras, a segunda questão diz respeito ao que é, na vida do homem, o maior dos bens ${ }^{5}$. Assim, a conclusão expressa que é dificil determinar o que é próprio de uma vida feliz e determinar qual é o maior dos bens na vida.

A essas formulações retiradas da conclusão da argumentação cabe relacionar o modo como Aristóteles se expressa na introdução do mesmo trecho. Lá, Aristóteles afirma que é sobretudo dificil julgar acerca do que na vida cabe escolher [o que é aipetóv] e satisfaria plenamente o desejo de quem o obtivesse. A noção do que é aipetóv, no atual contexto, evoca o início do capítulo 2, onde Aristóteles afirma que todo aquele capaz de viver segundo a sua própria escolha "estabelece algum alvo do viver belamente (...) visando o qual executará todas as ações” (1214b6-9). Tendo essa passagem em mente, vê-se que o [maior] dos bens na vida corresponde àquele que, tendo sido escolhido como alvo do viver belamente tem como resultado o bem viver, ou seja, a vida feliz. O que é próprio da 
vida feliz em oposição a uma vida qualquer é o que se segue na medida em que alguém executa toda as ações tomando o maior dos bens na vida como alvo.

A dificuldade que Aristóteles quer indicar, portanto, diz respeito à objetivação dessa estrutura geral.A dificuldade aparece diante de alguém que já toma como certo que a felicidade supõe a escolha correta do maior dos bens como alvo com vistas ao qual tudo mais é feito. O problema surge quando se tenta determinar qual é esse bem.

De acordo com o início de I 5, a maioria das pessoas acha que é fácil identificar qual é o bem que deve ocupar essa posição arquitetônica. Vários autores expressam surpresa com os argumentos que Aristóteles apresenta para mostrar que essa opinião está equivocada. DIRLMEIER (1984, p. 170) e GIGON (1971, p. 117) esperariam um exame dos diferentes fins que são ordinariamente apontados pelas pessoas, ao longo do qual Aristóteles mostraria que cada um deles é insatisfatório. Com isso, seria possível ver que a dificuldade para se determinar o que é o bem na vida é maior do que usualmente reconhecido. Aristóteles, no entanto, adota outro curso de ação: Ele apresenta uma série de situações nas quais não viver seria melhor do que viver.

Em diferentes formulações, a máxima segundo a qual não viver é melhor do que viver ocorre cinco vezes no trecho em questão (expressamente em 1215 19 , 21, 26, 30 e, de maneira menos explícita, em 34). Não são claras as relações entre as diferentes situações que motivam a enunciação da máxima nem tampouco o modo como elas permitem apreender a dificuldade relativa à identificação do que seja a felicidade. Procuraremos, aqui, determinar como essa argumentação pode estabelecer o resultado pretendido e qual sua importância para a discussão geral acerca da felicidade.

\section{Os cenários em contraste}

O trecho em questão estende-se do início de EE I até $1216^{\mathrm{a}} 10$. Apresentaremos, a seguir, nossa tradução para o trecho na íntegra, para, então, passarmos ao seu exame. 
[Preâmbulo] Se não é fácil julgar corretamente acerca de muitos outros assuntos, é sobretudo dificil julgar acerca do que a todos parece ser o mais fácil e cujo conhecimento parece pertencer a todo homem: o que na vida cabe escolher [aipetóv] e satisfaria plenamente o desejo de quem o obtivesse.

[A] Com efeito, muitos eventos são tais que em virtude deles as pessoas desistem de viver, por exemplo, doenças, dores extremas e calamidades, de modo que, se houvesse escolha, é evidente que, ao menos em virtude dessas coisas, seria de se escolher desde o início não ter nascido.

[B] Em adição a essas coisas, a vida que as pessoas levam quando ainda são crianças é desse tipo, pois ninguém em sã consciência suportaria retroceder novamente até ela.

[C] Além disso, muito do que não comporta qualquer prazer ou dor ou do que comporta prazer, mas não um que seja belo, é de tal natureza que o não ser é melhor do que o viver.

[D] Em geral, se alguém reunisse todas as coisas que fazem e pelas quais passam todos, mas nenhuma delas voluntariamente (por não ser em razão dela própria), e se aplicasse uma quantidade ilimitada de tempo, não se escolheria, com vistas a essas coisas, antes viver do que não viver. [E] Na verdade, ninguém preferiria viver pelo prazer apenas da comida ou do sexo, tendo sido excluídos os demais prazeres que o conhecer ou o ver ou algum dos outros sentidos dá aos homens, a menos que fosse um completo escravo. Com efeito, é evidente que àquele que fizesse essa escolha em nada diferiria nascer animal ou homem. Tanto é que o boi venerado no Egito como Ápis, em muitas de tais coisas é mais abastado do que muitos monarcas.

$[F]$ Semelhantemente, tampouco pelo prazer do sono, pois em que difere dormir um sono indesperto do primeiro dia até o último de mil anos ou quantos forem e viver sendo um vegetal? Os vegetais parecem participar de uma vida desse tipo, assim como os embriões. Também esses, com efeito, seguem crescendo (desde a primeira gênese na mãe), mas dormindo o tempo todo.

[Conclusão] Desse modo, é evidente, a partir dessas coisas, que escapa aos que investigam o que é o bem viver e o que é o bem no viver. 
Antes de discutir como é possível, a partir dessa argumentação, identificar a dificuldade relativa à enunciação do que é a felicidade, cabe examinar de que modo as situações apresentadas nas diferentes partes do texto tornam não viver preferível a viver.

Todo o trecho [A]-[F] está sob a égide da ideia segundo a qual não viver é melhor do que viver. Há uma alternativa entre escolher a vida ou preferir a morte que perpassa o trecho todo e a ideia segundo a qual a opção pela morte - considerando-se o que foi examinado - é mais vantajosa. As condições a partir das quais são avaliados os fatores que levam a essa conclusão, no entanto, variam consideravelmente de $[\mathrm{A}]$ para $[\mathrm{E}]-[\mathrm{F}]$. Na verdade, há um claro contraste entre a situação caracterizada em [A] e aquelas discutidas em $[\mathrm{E}]-[\mathrm{F}]$. Com isso em vista, começaremos examinando o contraste entre $[\mathrm{A}]$ e $[\mathrm{E}]-[\mathrm{F}]$ para, depois, verificar como se devem inserir as porções restantes do texto na discussão.

Em [A], Aristóteles faz referência a eventos aos quais se é submetido na vida e em vista dos quais seria mais vantajoso não ter nascido. São exemplos desses eventos as doenças, dores extremas e calamidades. Aristóteles

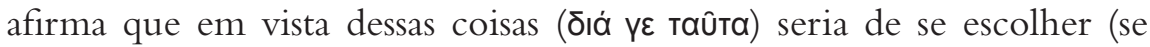
houvesse escolha) não ter nascido.

Nesse trecho, os eventos mencionados são exemplos de males que, considerados em si mesmos, seriam evitados por qualquer um que fosse capaz. Nesse quadro, é razoável entender que o que fundamenta a escolha pela morte é o fato que o evento considerado é, ele próprio, evitável em qualquer situação.

O texto claramente pretende estabelecer que a preferência por não viver decorre da consideração dos fatores apresentados, tomados em si mesmos e à exclusão de tudo mais. No trecho [A], a conclusão segundo a qual seria preferível não ter nascido é estabelecida com base na consideração de eventos como doenças, dores e calamidades, tomados à parte do que mais possa ocorrer ao homem 6 . Em outras palavras, a posição que o leitor em sua primeira leitura extrai desse trecho é aquela segundo a qual não valeria a pena seguir vivendo se a vida fosse integralmente composta pelos eventos mencionados. Dado que os itens considerados (calamidades, etc.), tomados em si mesmos, devem ser evitados, uma vida composta integralmente por tais itens deve ser, igualmente, evitada.

Em $[\mathrm{E}]-[\mathrm{F}]$, a situação discutida altera-se significativamente em relação ao que ocorre em [A]. Em [E], Aristóteles afirma que "ninguém preferiria 
viver pelo prazer apenas da comida ou do sexo (...) a menos que fosse um completo escravo" (1215 $30-35)$. Aqui, o exame das alternativas viver versus não viver está associado à avaliação de uma possível justificativa para a escolha da primeira opção. A opção que é contrastada com a morte não é, sem mais, a vida, mas a vida pelo prazer da comida e do sexo. Diante de uma alternativa exaustiva entre viver por tais prazeres ou não viver, a preferência de um homem digno recai sobre a segunda opção. Em [F], a mesma análise é expandida com o mesmo resultado para outro tipo do prazer, a saber, aquele associado ao sono.

No quadro anterior, a natureza desfavorável dos itens examinados motivava a escolha pela morte. Na nova situação, no entanto, não há nenhuma razão sugerindo que os itens considerados (certos prazeres corpóreos e o prazer do sono), tomados em si mesmos, devam ser evitados. Nada indica que Aristóteles tenha em mente uma situação de exagero, na qual a busca pelo prazer torna-se evidentemente danosa, nem que tenha em vista possíveis consequências deletérias dos prazeres físicos. A partir de sua ocorrência nesse texto, não há razão para não tomar o prazer físico como um bem. Neste novo caso, portanto, a preferência pela morte não é justificada pela ocorrência na vida de algo que deva ser evitado. Neste ponto do texto, é a escolha de uma vida com vistas a um certo tipo de bem que não é melhor do que a morte.

Os trechos $[\mathrm{A}]$ e $[\mathrm{E}]-[\mathrm{F}]$, portanto, caem ambos sob o paradigma comum de exibir uma certa situação na qual não viver é preferível a viver. Pode-se entender, no entanto, que a natureza da situação é consideravelmente diferente em cada caso. No primeiro trecho, Aristóteles discute de que modo os males podem tornar a morte preferível à vida. No segundo, examina-se de que modo os bens podem levar à mesma escolha. Em termos gerais, o resultado de cada um dos trechos pode ser expresso, respectivamente, do seguinte modo:

1) Viver uma vida composta exclusivamente por males é pior do não viver.

2) Viver uma vida com vistas a certos bens é pior do que não viver.

A diferença mais notável entre os dois cenários diz respeito ao papel que a indicação de uma justificativa desempenha em cada um deles. No primeiro caso, a preferência pela morte é fundamentada por um fator que a torna melhor do que a vida. No segundo, essa preferência decorre do 
fato que um certo fator é incapaz de justificar a escolha pela vida. O primeiro cenário é compatível com a ideia segundo a qual permanecer vivo é, em princípio, melhor do que perecer. Não se sugere, então, que a opção de permanecer vivo precise de justificativa. Ao invés disso, é a conclusão contrária que carece de uma justificativa. O segundo cenário, por sua vez, supõe que a escolha pela vida deva ser fundamentada. Se as justificativas disponíveis são insatisfatórias, impõe-se a preferência por não viver.

\section{A escolha humana pela vida carece de justificação}

Com respeito à necessidade da justificação, o quadro apresentado em [E][F] não é, de início, intuitivo. Por que a escolha da vida em detrimento da morte precisaria de uma justificativa? Se seguir vivendo ou optar pela morte são as duas alternativas em pauta, é a segunda opção que parece precisar de uma motivação especial.

A inversão na ordem do que requer uma justificativa deve-se a uma alteração significativa entre as suposições em jogo no primeiro e no segundo cenário considerados. Em [E]-[F], ao contrário do que ocorre no início da argumentação, está em questão o que é próprio do ser humano em oposição ao que é compartilhado com animais e plantas. Nesse trecho, Aristóteles está tratando de escolhas que são distintivas do ser humano. Trata-se, portanto, não simplesmente de escolher a vida, mas de escolhê-la tal como faz um homem. Essa é a escolha que carece de justificativa. De acordo com essa ideia, seria possível sustentar que, se nos parece intuitivo que viver é sem mais melhor do que não viver, isso se deve ao instinto de sobrevivência que compartilhamos com os demais seres vivos. Aos que pretendem fazer a escolha própria de um homem pela vida, por outro lado, seria necessário acompanhar tal escolha de uma justificação.

Para compreender a natureza dessa exigência, cabe fazer referência ao início de EE I 2 - texto que é posto no horizonte de I 5 a partir da referência, no início do texto, a um bem que deve ser escolhido e satisfaria plenamente o desejo de quem o obtivesse. Em EE I 2, Aristóteles afirma que "todo aquele capaz de viver segundo a sua própria escolha estabelece algum alvo do viver belamente, quer seja a honra, quer a reputação, quer a riqueza ou cultura, visando o qual executará todas as 
ações (já que não ordenar a vida em direção a algum fim é sinal de muita estupidez)" (12146-11).

A cláusula entre parênteses deixa claro que há uma razão muito forte para que um homem estabeleça um fim com vistas ao qual é ordenada a vida. A partir de uma leitura cruzada dos trechos relevantes de EE I 2 e I 5 , pode-se sugerir que essa razão corresponde à ideia segundo a qual não há vida propriamente humana que não seja ordenada com vistas a um fim. Diante disso, apenas um tolo não ordenaria a própria vida com vistas a um fim, se a ele estivesse dada tal escolha.

Evidentemente, não se está determinando com isso qual ou quais fins ensejam a realização máxima de uma vida humana. A adoção da hipótese que estamos introduzindo estabelece apenas que alguém que viva uma vida genuinamente humana toma para si algum fim com vistas ao qual são executadas todas suas ações. Nada se disse a respeito da natureza desse fim (nem mesmo que esse fim deva corresponder a um bem singular ao invés de um composto de vários bens).

Para os nossos propósitos atuais importa notar que, se o caráter humano da vida depende do estabelecimento de um fim, então, escolher uma vida propriamente humana depende da escolha de um fim. Sendo assim, todo aquele que alegue viver genuinamente como um homem deve estar preparado para responder a questão “com vistas a que você vive?". Nesse sentido, a escolha pela vida propriamente humana carece de uma justificativa na medida em que tal escolha depende da escolha de um fim.

Essa associação entre o caráter humano da vida e a escolha de um fim, cremos, é fundamental para a compreensão do cenário caracterizado a partir de $[\mathrm{E}]-[\mathrm{F}]$. Resta, no entanto, um elemento adicional. Em [E]-[F], como sustentamos, Aristóteles parte de um quadro no qual a escolha de um homem por viver em oposição a não viver carecia de uma justificativa. Ora, a associação entre o caráter humano da vida e a escolha de um fim não é suficiente para estabelecer a necessidade de uma justificativa para viver sem mais. Seria possível sustentar conjuntamente que a escolha pela vida propriamente humana careça de uma justificativa, ao passo que a escolha por simplesmente estar vivo em oposição a não viver não careça. Nesse caso, da inexistência de um fim com vistas ao qual se vive não se segue que a morte é a melhor opção, ainda que a ausência de um fim torne impossível viver uma vida propriamente humana. O cenário extraído 
de [E]-[F], portanto, deve incluir uma suposição adicional, a saber, aquela segundo a qual, para um homem, não viver é melhor do que viver uma vida que não seja propriamente humana. Diante dessa suposição e da associação estabelecida anteriormente, tem-se que a ausência de um fim, ao impossibilitar a adoção de uma viva humana genuína, torna a morte a opção de preferência para um homem digno. Desse modo, é possível inserir o contexto de [E]-[F] sob o domínio da máxima "não viver é melhor do que viver" porque Aristóteles está operando com a ideia segundo a qual a escolha de um fim fornece uma justificativa para a escolha de um homem pela vida e, sem uma tal justificativa, um homem consideraria melhor não viver ${ }^{8}$.

\section{Por que é difícil dizer o que é o bem humano?}

Tendo examinado as situações de maior contraste em [A]-[F], podemos retornar ao problema inicial e discutir o modo através do qual a argumentação apresentada no trecho mostraria que identificar o bem humano é mais dificil do que se reconhece usualmente.

Propusemos acima que as opiniões que Aristóteles tem em mira no início de EE I 5 são formuladas a partir da aceitação da ideia de acordo com a qual a felicidade supõe a escolha correta do maior dos bens como alvo. O ponto a ser combatido corresponderia à ideia segundo a qual é fácil identificar um fim que possa ser tomado como alvo de todas as ações. Tal ideia só se sustenta quando não são levadas em conta as condições que devem ser satisfeitas por qualquer candidato a ocupar a posição de fim. O propósito de Aristóteles no capítulo seria justamente o de indicar condições às quais está subordinada a escolha do fim apropriado e que são usualmente negligenciadas pelas pessoas. É com vistas à consecução desse objetivo que Aristóteles recorre às situações nas quais não viver seria melhor do que viver. A dificuldade fundamental que a compreensão do trecho enfrenta é identificar o modo como esse recurso pode contribuir para a obtenção do objetivo.

A nosso ver, essa dificuldade surge, em grande medida, da situação que foi caracterizada a partir de [A]. Por que, para mostrar que é difícil encontrar um fim apropriado para a vida humana, seria proveitoso recorrer às 
situações em que males tornam penosa a vida? De outra parte, o contraste entre $[\mathrm{A}]$ e $[\mathrm{E}]-[\mathrm{F}]$ aponta para uma dificuldade quanto à unidade da argumentação. Dadas as diferenças entre as situações caracterizadas em cada um dos dois trechos, torna-se difícil conjugá-los em um argumento coerente ${ }^{9}$.

Para unificar o percurso da argumentação apresentada entre [A] e [F] de modo que nela se encontre um meio de obter o objetivo que Aristóteles estabelece para o trecho, sugerimos considerar que a suposição extraída do exame de [E]-[F] está em voga desde o início da argumentação. Aristóteles tomaria como opinião aceita aquela segundo a qual um homem prefere não viver a viver sem um fim para sua vida. Seu objetivo seria combater a posição de quem aceita essa suposição e considera que é fácil encontrar um fim para a vida humana.

O procedimento de Aristóteles em EE I 5, em linhas gerais, corresponderia a mostrar que, dadas as condições que devem ser satisfeitas pelo fim com vistas ao qual são executadas todas as ações, há poucas coisas na vida que se qualificam como candidatos viáveis a ocupar a posição de tal fim. Em cada etapa da argumentação, um novo tipo de item seria testado com resultado negativo. Assim, seriam progressivamente excluídos do âmbito do que pode contar como fim os itens mencionados em [A], em [B] e assim por diante ${ }^{10}$. Como está valendo desde o início a suposição de que um homem prefere não viver a viver sem ordenar a vida com vistas a um fim apropriado, a conclusão tem por consequência que um homem, ao menos com vistas às coisas consideradas no trecho em questão, preferiria não viver. Tentar estabelecer como fim algo que não pode desempenhar esse papel corresponde a deixar vaga a posição de fim. Para quem prefere não viver a viver sem um fim, essa situação resulta na preferência pela morte.

Nessa perspectiva, o trecho [A] não teria por fim explorar um cenário distinto daquele discutido em $[\mathrm{E}]-[\mathrm{F}]$. Todo o argumento de $[\mathrm{A}]-[\mathrm{F}]$ seria dominado pela ideia segundo a qual há um fim que deve justificar a escolha humana pela vida. O objetivo do trecho [A] seria o de apontar as coisas que mais evidentemente não podem desempenhar o papel de fim. Obviamente, algo que tornaria insatisfatória mesmo uma vida que não carecesse de justificativa não pode ocupar a posição do fim que justifica a escolha humana pela vida.

Tem-se, em [A], um primeiro movimento para desafiar a impressão segundo a qual é fácil encontrar um fim. Trata-se, na verdade, de um 
movimento ainda modesto, uma vez que se exclui por meio dele apenas hipóteses que ninguém imaginaria tomar como fins. O objetivo do trecho é apenas dar início, a partir do que é evidente, à argumentação que posteriormente gerará os resultados relevantes: o que torna a vida indesejável evidentemente não pode corresponder ao fim que justifica a escolha pela vida.

Em [B], Aristóteles recorre a uma opinião negativa sobre a infância que é expressa em mais de um ponto da sua obra (por exemplo, Pol.VII, 1,1323b34; ver também EN 1174ª1-3; 1154b-11) para incluí-la no conjunto de eventos ou fatores que tornariam mais vantajoso não viver. $\mathrm{A}$ ideia central não parece diferir daquela exposta em [A]: ninguém passaria pela infância se tivesse escolha e uma vida integralmente restrita a ela seria mais penosa do que a morte. A infância não pode ser tomada como fim que justifica a escolha pela vida do mesmo modo que não podem fazê-lo as doenças ou calamidades.

O trecho [C] começa a tomar distância do conjunto de itens que evidentemente tornariam indesejável viver mesmo que não fosse necessário justificar a escolha da vida. Essa porção do texto não apresenta itens que correspondem inequivocamente a males. Talvez seja possível associar aos males os prazeres que não são belos (provavelmente prazeres vergonhosos ou imoderados), mas esse não parece ser o caso do que não comporta prazer ou dor. Não parece que uma vida repleta de eventos desse tipo possa ser tomada como pior do que a morte a mesmo título que a vida repleta de calamidades. Como se viu, seria possível concluir que é melhor morrer do que viver uma vida tomada por sofrimentos e calamidades mesmo quando se supõe que permanecer vivo é, em princípio, melhor do que perecer. Isso não seria verdadeiro de uma vida cheia do que não traz prazer ou dor. Se a opção natural recai sobre a vida em detrimento da morte, não parece possível que os eventos neutros quanto à dor e ao prazer possam justificar a opção oposta. $\mathrm{Na}$ verdade, a única razão pela qual os itens mencionados em [C] estão associados à opção por não viver é a suposição segundo a qual opção humana pela vida depende da escolha de um fim. Itens que não comportam prazer ou dor (ou que comportam prazer não-belo) evidentemente não podem ser tomados como fins e, portanto, não se escolheria viver com vistas a eles.

Em [D], Aristóteles considera o conjunto genérico do que se faz ou sofre de maneira não voluntária. Essa categoria abarca os itens considerados 
em [A], [B] e [C] anteriores e o trecho, em sua porção final, torna expresso o modo como estão sendo testados todos os itens desde [A]: "não se

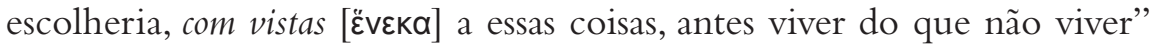
$\left(1215^{\mathrm{b}} 30\right)$.

No trecho [D], Aristóteles torna clara uma das condições que devem ser satisfeitas por candidatos a ocupar a posição de fim. Como se explica em 1215 $27-28$, nenhum dos itens considerados nos trechos iniciais da argumentação pode ser tomado como fim porque não se faz ou sofre qualquer um deles em razão deles próprios. Desse modo, apenas itens que são feitos ou pelos quais se passa em razão deles próprios podem ser apresentados como candidatos a fins.

A condição mais restritiva ao que pode ocupar a posição de fim, no entanto, é apresentada nos trechos [E]-[F]. Em [A]-[D] Aristóteles aponta para os itens que, não sendo bens, não podem ser tomados como fins. Em [D] é claro apenas que males e itens neutros (como o que não comporta prazer ou dor) não podem justificar a escolha humana pela vida porque ninguém os tomaria como fins. Em [E]-[F], por sua vez, Aristóteles estabelece uma restrição quanto aos bens que, tomados como fins, são compatíveis com a escolha humana pela vida. Bens que não são especificamente humanos, quando tomados como fins, não resultam em justificativas apropriadas à escolha humana. O que há de humano em uma vida ordenada com vistas a um fim (em oposição à vida desordenada) perde-se quando o fim escolhido não é característico de uma vida humana. Ainda que escolher um fim com vistas ao qual se vive seja próprio do homem em oposição aos outros seres vivos, quem escolhe um fim animalesco escolhe viver a vida de um animal e, assim, exclui-se do âmbito da vida humana.

Desse modo, mesmo que os prazeres do sexo, da comida ou do sono sejam bens genuínos, eles não justificam a escolha pela vida em detrimento do não-viver porque não são prazeres especificamente humanos. Se uma vida farta de comida e sexo pode ser em algum sentido uma boa vida, essa não é a boa vida de um homem, mas de um animal. Talvez seja possível dizer que, se um animal tem assegurado suficiente alimento e sexo, para ele a vida é mais vantajosa do que a morte. No entanto, não seria em virtude desses prazeres que um homem digno faria a escolha pela vida em detrimento da morte. De modo semelhante, tampouco o prazer 
do sono é capaz de justificar a escolha de um homem pela vida. A vida do sono, afinal, é própria de um vegetal.

Em vista do que acaba de ser exposto, é possível unificar a argumentação de $[\mathrm{A}]$ a $[\mathrm{F}]$ a partir do objetivo de mostrar que cada um dos tipos de itens considerados é incapaz de ocupar a posição do fim com vistas ao qual o homem executa todas as ações: ao longo dos diferentes trechos, são eliminados os males, os itens neutros quanto a prazer e dor e, em resumo, tudo o que não é feito com vistas a si próprio e, finalmente, o bens que não têm caráter propriamente humano. Com isso, Aristóteles teria exibido algumas das condições que devem ser satisfeitas para que algo ocupe a posição de fim e que costumam ser ignoradas por aqueles que acreditam ser fácil dizer o que é o maior bem na vida.

${ }^{1}$ O presente trabalho foi realizado com apoio da CAPES, entidade do Governo Bransileiro voltada para a formação de recursos humanos. O autor é pesquisador colaborador da Universidade Estadual de Campinas e Bolsista de Produtividade em Pesquisa do CNPq.

${ }^{2}$ Ver GIGON, 1971, p. 115-118, que enfatiza as dificuldades quanto à compreensão da unidade interna do trecho, DIRLMEIER, 1984, que considera frouxa a conexão do raciocínio com o contexto (p. 170) e ROWE (1971), para quem o trecho pareceria ter sido transcrito do diálogo Eudemus "sem qualquer atenção real ao contexto" (p. 76, n.1). De acordo com Rowe, o propósito do trecho para a EE seria "quase irrelevante" (p. 17, n. 4).

${ }^{3}$ As traduções das citações da Ética Eudêmia aqui apresentadas resultam de trabalho conjunto do autor e da colega Inara Zanuzzi. As decisões com relação às versões aqui adotadas, no entanto, são de responsabilidade do autor e não refletem necessariamente a posição de Inara Zanuzzi. Utilizou-se como texto de base a edição de WALZER e MINGAY (1991).

${ }^{4}$ Em português, há poucos recursos para marcar a distinção entre as duas expressões gregas. Em particular, a mesma palavra "bem" deve traduzir o advérbio દủ na primeira expressão e o substantivo áyađóv na segunda. Outras línguas modernas estão em melhores condições de expressar o contraste (veja-se, por exemplo, as traduções inglesas, que optam por "well" para a primeira expressão e "good” para a segunda: KENNY, 2011; INWOOD; WOOLF, 2013).

${ }^{5}$ Aristóteles não raro utiliza a expressão tò áyäóv pelo superlativo to äpıøtov (ver vocábulo áyäós em BONITZ, 1870), que seria mais natural para o contexto.

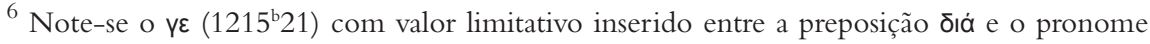
TaûTa, que, em conjunto, estabelecem a conexão de consequência entre os fatores considerados e a conclusão que enuncia a preferência por não viver em detrimento de viver.

${ }^{7}$ Mesmo na discussão detida acerca do prazer desenvolvida em Ética Nicomaqueia (EN) VII (livro comum à EE), Aristóteles admite que há valor no prazer físico - ainda que tal prazer deva ser buscado com moderação: EN VII 14, 1154ª $8-21$.

doispontos, Curitiba, São Carlos, vol. 10, n. 2, p.357-371, outubro, 2013 
${ }^{8}$ J.WHITING (2012) aponta para uma noção semelhante quando observa que, ao contrário do que ocorre na Ética Nicomaqueia, na Eudêmia seria proeminente a ideia de "algo com vistas ao qual é de se escolher vir a ser ao invés do contrário" (p. 101). Ela entende que a mesma ideia retorne em EE VII 12, onde a argumentação tomaria por base que "o desejo por viver não é [compreendido] como primitivo, mas como algo a ser explicado pelo valor das atividades nas quais consiste nosso viver" (ibid.).

A leitura de W. JAEGER (1948) de EE I 5 também explora a hipótese segundo a qual nesse capítulo é fundamental a ideia de que o valor da vida depende de um bem que se tome como fim (p. 251-258). Para JAEGER, no entanto, esse bem em EE I 5 corresponde exclusivamente

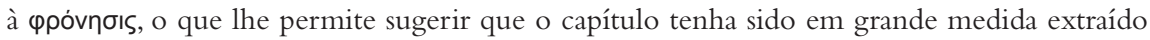
do Protrepticus. Suas comparações entre os fragmentos dessa obra e EE I 5, contudo, não nos parecem conclusivas. Tampouco cremos que seja possível identificar em EE I 5 uma prece-

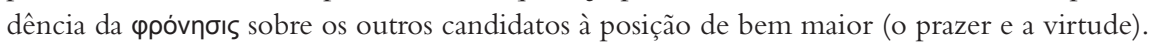

${ }^{9}$ Remetemos a GIGON, 1971, p. 115 ss., que enfatiza sobremaneira as dificuldades mencionadas neste parágrafo.

10 Interpretações que desenvolvem propostas que seguem nessa direção são sugeridas por BUDDENSIEK (1999, p. 57-59) e KENNY (1978, p. 194-195).

\section{Referências bibliográficas}

Edições e traduções das obras de Aristóteles

BYWATER, I. 1942.Ethica Nicomachea. Oxford, Clarendon.

INWOOD, B.; WOOLF, R. 2013. Eudemian Ethics. Cambridge, Cambridge U. P.

KENNY, A. 2011. The Eudemian Ethics. Oxford, Oxford U. P.

ROSS, W. D. 1957. Politica. Oxford, Clarendon.

WALZER, R. R.; MINGAY, J. M. 1991. Ethica Eudemia. Oxford, Clarendon.

Demais obras

BONITZ, H. 1870. Index Aristotelicus. Berlim, Typis et impensis Georgii Reimerii.

BUDDENSIEK, F. 1999. Die Theorie des Glücks in Aristoteles' Eudemischer Ethik. Göttingen, Vandenhoeck \& Ruprecht.

DIRLMEIER, F. 1984. Eudemische Ethik. Berlin, Akademie-Verlag. 
GIGON, O. 1971. Das Prooimion der EE. In: MORAUX, P.;

HARLFINGER, D. Untersuchungen zur Eudemischen Ethik. Berlin, Walter de Gruyter.

JAEGER, W. 1948. Aristotle - Fundamentals of the history of his development. Oxford, Clarendon.

KENNY,A. 1978. The Aristotelian Ethics. Oxford, Oxford University Press.

ROWE, C.J. 1971. The Eudemian and Nicomachean Ethics: a study in the development of Aristotle's thought. Proceeding of the Cambridge Philological Association, Supplement 3.

WHITING, J. 2012. Prolegomenon to a complete reading of EE VII.12. In: LEIGH, F. The Eudemian Ethics on the voluntary, friendship and luck. Leiden, Brill. 